\title{
Tensiones histórico-antropológicas: a propósito de La utopía tupamarista de Jan Szeminski. Perú siglo XVIII.
}

Historico-anthropological tensions: On La utopía tupamarista by Jan Szeminski. Peru s. XVIII.

\author{
Germán Morong Reyes \\ Universidad Bernardo O’Higgins, Chile \\ german.morong@ubo.cl
}

\section{Resumen}

Tomando en consideración la obra La utopía tupamarista (1983) de Jan Szeminski y evaluando el estatuto metodológico de la historia y la antropología, en función de sus interlocuciones, se propone un ejercicio crítico que pone en discusión el carácter estático de la identidad étnica, perspectiva analítica que durante la década de los 80 ' fue utilizada para entender la discursividad medular de la rebelión de Tupac Amaru II (1781-82). Se cuestiona, a partir de una posición metodológica históricocontextual, la lógica esencialista de la visión indígena operante en el siglo XVIII colonial.

Palabras clave: Túpac Amaru II; visión indígena; historia; antropología; continuidad cultural.

\begin{abstract}
Considering the work La utopía tupamarista (1983) by Jan Szeminski and evaluating the methodological statute of history and anthropology on the basis of their exchanges, this work seeks to outline a critical exercise that questions the static nature of the ethnic identity, an analytic perspective that was used during the eighties to understand the central discursive logic of the Tupac Amaru II rebellion (1781-82). From a historical-contextual methodological position, this work questions the essentialist logic of the functioning indigenous worldview during the colonial XVIII c.
\end{abstract}

Keywords: Tupac Amaru II; indigenous worldview; history; anthropology; cultural continuity.

Tensiones histórico-antropológicas: a propósito de La Utopía Tupamarista de Jan Szeminski. Perú siglo XVIII.

Sur y Tiempo. Revista de Historia de América, №1, enero-junio 2020, pp. 1-19.

ISSN 2452-574X

DOI: $10.22370 /$ syt.2020.1.2044

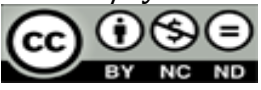




\section{Problematización: un periplo historiográfico por etapas}

A comienzos de la década de 1780 se desarrolló la insurrección anticolonial más grande que viera el período colonial en la América hispana (Walker, 1999, p. 15-33). Su líder, José Gabriel Condorcanqui (Túpac Amaru II), dirigió un discurso insurgente no sólo a la población india, sino a vastos sectores sociales adscritos a las llamadas "castas coloniales" (indios, mestizos, criollos, etc.), cuyos intereses respondían a condenar la mala administración peninsular que diezmaba la capacidad tributaria de un vasto espectro social1. Esta gran rebelión fue considerada, en muchos casos, como un precedente inmediato de las revoluciones liberales por medio de las cuales se constituyeron los estados nacionales latinoamericanos (en que comenzó a ser significativa la "peruanidad"). También se la representó como el retorno al prístino estado inca y su justa administración basada en sistemas reciprocitarios y redistributivos, sobre la base de concepciones milenaristas. Esto último posibilitó, entre los adherentes indígenas y mestizos, la creencia en un futuro que cobró la forma de utopía andina, una discusión en torno al milenarismo y el tiempo cíclico que algunos investigadores -historiadores, antropólogos- asumieron como un proceso de restitución del incario.

La emergencia de una historiografía sobre el proceso revolucionario y sus consecuencias (más allá de la indolente mirada decimonónica) se desarrolló como correlato al nacimiento del indianismo a mediados de la década de 1950. Como bien ha afirmado Serulnikov (2010: 5-10), la hegemonía coyuntural de ciertas narrativas marxismo, indianismo- posibilitaron una visibilización histórica del movimiento favorable a la agencia india y su determinante posición en los procesos emancipatorios del continente (Serulnikov, 2010: 6). En este sentido, y al amparo de los movimientos indígenas y su reconocimiento por parte de gobiernos reformistas ${ }^{2}$, la historiografía reivindicó el papel asumido por las castas subalternas en un primigenio y peregrino movimiento emancipador. Fueron los pioneros trabajos de Boleslao Lewin (1957), Carlos Valcarse (1977) y Jorge Cornejo (1949), los que instalaron la idea de que el movimiento tupamarista era el precursor de la

\footnotetext{
1 En general, la aplicación de las reformas borbónicas (1740-1780) en todo el virreinato peruano, a fines del siglo XVIII, fue configurando una reestructuración que modificó sustancialmente las condiciones de larga duración en que se desarrolló la convivencia bajo el pacto colonial entre la población indígena y la fiscalidad hispana. Tales nuevas condiciones han sido ampliamente discutidas por diversas corrientes historiográficas con distintas lógicas de análisis, asociadas a aspectos económicos, políticos y sociales. En este sentido, la historiografía ha tendido a ver en estas reformas las causales que permitieron la emergencia de las rebeliones anticoloniales (1740-1781), desde Juan Santos Atahualpa a Túpac Amaru II, la nueva situación político-social del indígena y el nacimiento de un sentimiento generalizado antihispanista. Tales reformas legalizaron el reparto forzoso de mercancías entre los indígenas, legitimando sistemáticamente el abuso de los corregidores, e instalaron un sistema de mita minera mucho más abusivo para las comunidades indígenas.

2 El de Juan Velasco Alvarado (1968-1975) como un claro ejemplo.
} 
independencia anticolonial y de la formación de los estados nacionales en América del sur, afirmando la estrecha relación entre el ideal criollo y las demandas étnicas (Rowe, 1976: 11-68). No obstante, y a poco andar, se desplomó esta argumentación en el sentido del evidente antagonismo entre las demandas indígenas y los intereses de la élite criolla.

En las décadas posteriores (1970-90) el análisis historiográfico del proceso tomó otro cariz; si la anterior preocupación analítica había sido la vinculación ideológica entre indios y criollos en pro de un ideal liberal-independentista, la generación posterior de investigadores realzó justamente esa diferencia. Es decir, la insistencia en mostrar la naturaleza estrictamente étnica del levantamiento, dejando fuera toda reivindicación "occidental” (Serulnikov, 2010: 7). Los eventos acaecidos en la lucha anti fiscal fueron interpretados como expresión de una cosmovisión andina que articularía la estructura material, simbólica e ideológica del discurso rebelde. Probablemente, el influjo de corpus epistemológicos hegemónicos como la historia de las mentalidades o la emergente antropología cultural fueron determinantes en la constitución específica de un nuevo objeto de estudio; la utopía andina. Entendida ésta como la proyección de un futuro cuya lógica se encontraba en una especie de pasado dorado y que sus defensores no sólo eran los propios líderes indios en el siglo XVIII, sino todo un medio intelectual bajo la égida de la nueva historia (Burke, 1996: 11-37). Esta tradición, de la utopía andina, tuvo exponentes de alto prestigio intelectual como lo fueron Alberto Flores Galindo (1987), Manuel Burga (1988) y Jan Zseminski (1983). No obstante, una nueva generación de historiadores peruanos "acusaría a sus mayores de reificar la cultura andina y atribuir a los pobladores indígenas un atavismo esencialista que no poseían ni deseaban ni en el siglo XVIII, ni en el siglo XX" (Serulnikov, 2010: 7).

Es precisamente entre la década de los setenta y noventa en que la rebelión de Túpac Amaru II va a ser entendida en su contexto inmediato (la conflictiva década de 1765-1785) y analizada desde sus causas materiales más fundamentales (Fischer, 1971; O’Phelan, 1995; Golte, 1980). El revisionismo historiográfico que fue empoderándose en los medios intelectuales peruanos e internacionales, permitió reconsiderar los documentos y los discursos rebeldes al amparo de una historia económica y social, cuya lógica respondía a entender históricamente las necesidades materiales y coyunturales que afectaban a las poblaciones andinas. Como también, reposicionar la agencia política de los líderes adscritos al movimiento rebelde más allá de sus memorias simbolizadas y resignificadas en el siglo XVIII (Serulnikov, 2010). Estos estudios, alejados de cuestiones puramente ideológicas, preocupados de entender la lógica documental a través de un orden de los acontecimientos allí descritos, mostraron con sobradas evidencias que las insurrecciones que se 
manifiestan claramente a partir de 1742 (O'Phelan, 1988: 117-130)3 eran plausiblemente producto de cuestiones de orden social económico como la legalización del reparto forzoso, la aplicación de las reformas borbónicas directamente relacionadas con el aumento de la alcabala y el establecimiento de aduanas. Para Scarlett O'Phelan (1995), las medidas adoptadas afectaron a todas las capas sociales de la población colonial; productores, comerciantes, comunidades indígenas. Tales medidas crearon un descontento generalizado en toda la región (todo el centro sur peruano, correspondiente a la denominación colonial del "Alto y el Bajo Perú").

La posición metodológica adoptada en investigaciones como las de Scarlett O’Phelan (1995), Jurgen Gölte (1980), Charles Walker (1999), Sergio Serulnikov (2010), entre otros, ha privilegiado el análisis documental a partir de sus contextos de producción, evidenciando que los discursos rebeldes poseían, a lo menos, dos dimensiones fundamentales; por un lado referían a reclamos políticos sobre situaciones coyunturales de extrema gravedad (la mita, el reparto forzoso, el abuso de los corregidores, los impuestos, etc.) y por otro, el contenido de estos constituía una situación que consideramos "polifónica". Esto quiere decir que el contenido de los discursos rebeldes estaba dirigido no a un solo segmento sociocultural, sino que al conjunto de los grupos sociales y castas cuyos intereses, en estricto rigor, eran divergentes. Se trató, en palabras de O'Phelan (1995: 13-37), de discursos paralelos, lo que pondría en cuestionamiento la coherencia interna de los "textos" tupamaristas. La autora con vehemencia se preguntaba en 1995: utopía andina, ¿para quién?

Las críticas -fundadas o no- a las posturas esencialistas evidenciaban una tensión entre historiadores y antropólogos, cuyo diálogo se había desarrollado a tropiezos en función de sus intereses disciplinarios y metodológicos. Ha debido recorrerse un largo periplo para que llegue a consolidarse un maridaje ininterrumpido, el de la antropología histórica. Pero en la década de los 80' y bien entrados los 90', la posición de muchos historiadores era denunciar el poco cuidado de la antropología, la etnología y la etnografía en comprender un fenómeno étnico a partir de sus continuidades estructurales asumiendo una postura esencialista de la cultura. Mucho de lo que subyacía a la utopía andina descansaba en presupuestos de esta índole. En este sentido, los trabajos de campo sobre las comunidades peruanas de la sierra y el altiplano promovieron aquella tentadora pero peligrosa táctica de comparar el material registrado en el ámbito etnográfico con los documentos tempranos del siglo XVI (sobre todo el trabajo interpretativo y heurístico sobre las crónicas hispanas de interés indígena), con documentos situados en los siglos XVII y XVIII (referidos a toda la burocracia económica y judicial emitida por los

\footnotetext{
3 La rebelión de Juan Santos Atahualpa se inscribe peregrinamente en la era de las "rebeliones
} 
funcionarios reales hispanos, que concernía a materias indígenas) y con una tradición oral rescatada en pleno siglo XX. Los materiales utilizados por antropólogos y etnohistoriadores provenían así de diversos espacios temporales en la constitución de su objeto de estudio: "la cultura indígena y su perduración". Perduración que operaba en el campo de las mentalidades, la memoria y los principios culturales andinos a partir de una variada gama de soportes de registros del pasado (oralidad, pintura, vestimenta, textualidad). Esta suerte de continuismo esencialista inundó las esferas intelectuales y se extendió tanto a la exégesis documental como al trabajo etnológico sobre comunidades étnicas sobrevivientes al devenir post-colonial. En 1987, Thérèse Bouysse-Cassagne y Olivia Harris sostenían que "aunque pueda parecer demasiado brusca la transición, queremos enfatizar de esta forma las continuidades evidentes en el pensamiento aymara desde la antigüedad hasta el presente" (1987, 11-59), argumento que pareció enardecer los ánimos de la generación de historiadores posteriores que, regresando a los contextos de producción documental, reclamaban el retorno de los discursos indígenas a los hechos concretos que les habían de dar su sentido último.

La argumentación precedente sugiere un cuestionamiento de los supuestos con los que se analizó el programa tupamarista y la discursividad que emanaba de él, vinculado a fuerza con una prístina visión indígena situada en los textos y objetos materiales de fines del siglo XVIII. Lo que cuestionamos, fundamentalmente, es la certeza de que la tradición incaica (Burga, 1988: 71)4 en su contenido original sea pensada por los dirigentes indígenas (quienes se asumen dentro de la genealogía real inca) y por las comunidades nativas, en su mayor número ágrafas. Los supuestos continuistas tuvieron un ejemplo flagrante en la obra La utopía tupamarista del investigador Jan Zseminski. Esta obra ejemplifica el problema que suscita en términos metodológicos la afirmación de una continuidad cultural (siglos XVI-XVIII) indolente al cambio histórico (en su amplio sentido). El distinguido investigador va a afirmar que la visión del tiempo-espacio y la memoria "histórica" de los insurrectos traza una continuidad reivindicativa con las lógicas de pensamiento nativo que aún operaban a mediados del siglo XVI. En otros términos, las concepciones milenaristas que supuestamente gobernaban la producción discursiva de las élites incaicas en medio de la catástrofe de la conquista entre 1565 y 1575 , podían encontrarse sin alteraciones en las proclamas que los indígenas y mestizos enunciaban en 1781. En este sentido, la hipótesis fundamental de Jan Szeminski es sostener que "durante el siglo XVIII tuvo que existir una visión indígena -propia y no europea del futuro- simultáneamente a los programas formulados por los no-indígenas" (Szeminski, 1983: 9).

andinas"

${ }_{4}$ Esta categoría de análisis, contrapuesta a las irrupciones que nos propone la exégesis histórica, fue un criterio investigativo en la década de los $80^{\prime}$. 
Comenzamos este recorrido con algunas interrogantes que impugnan las argumentaciones fundamentales del autor; ¿De qué utopía hablamos al analizar el programa rebelde? ¿Cómo piensa la elite cusqueña, presente en el movimiento de Túpac Amaru II, la tradición incaica? ¿Cuál es la táctica documental para suponer ciertas estructuras de larga duración? Nos proponemos evaluar algunas de las hipótesis de la La utopía tupamarista en función de advertir los elementos tensionantes que friccionaron la actual relación de maridaje entre dos prácticas disciplinarias.

\section{La utopía tupamarista, la continuidad cultural como perspectiva analítica}

La obra, escrita entre 1978 y 1982 pero publicada en 1983 y reeditada en 1993, representa el esfuerzo intelectual por comprender la lógica del programa tupamarista y el sentido "indigenista" que lo subyacía. El texto de Szeminski consta de dos partes de las cuales se sirve el autor para entender, en el contexto del programa rebelde, dos lógicas de razonamiento (occidental y autóctona) que diferencian los conceptos hispanos de la representación temporo-espacial de la elite inca presente en el siglo XVIII. A saber: Parte I: "Pensando en Español", en las que se incluyen los capítulos "Sobre el significado de algunos términos empleados en los documentos" y "Sobre la comprensión de la independencia". Por otro lado, la Parte II, "Runa Simiwan Yuyasqa", esta última consta de cuatro capítulos de los cuales nos interesa comentar los siguientes "Sobre el tiempo-espacio en el Tawantinsuyu" y "Sobre la existencia de formas que continuaron la organización social incaica y la concepción de tiempo-espacio en la época de la revolución tupamarista". Específicamente aludimos -para efectos del objetivo propuesto- a la segunda parte, pues es allí donde se asumen los supuestos declarados y donde no existe un deslinde claro entre dos prácticas disciplinarias. Antes sí, un comentario a esta primera parte.

\subsection{Pensando en español: documentos, conceptos y percepción social}

En la primera parte de la obra apreciamos sugerentes aproximaciones para tratar el problema de la insurrección. El autor pone en evidencia una serie de conceptos que señalan una diferenciación social clasificada y supuestamente comprendida y aceptada en el siglo XVIII. Advierte la existencia de diferenciación por casta, clase, estamento y cargo. La búsqueda de una serie de designaciones que prueben la existencia de tales divisiones se sostiene sobre un único fondo documental al cual el autor recurre casi durante todo el libro. De él dependen o se sostienen las hipótesis propuestas y se infieren las posibles diferencias sociales; nos referimos a la Colección Documental de la independencia del Perú, colección que reúne casi mil documentos incluidos en cuatro volúmenes (Szeminski, 1983: 11). 
La lectura que efectúa Szeminski de los documentos tiende a revalorar o a reconsiderar el significado que poseen ciertos términos, a veces vistos como "evidentes" (en su traducción o sentido literal) con relación a lo que "realmente" (entiendo históricamente) ellos están significando. Szeminski parte del supuesto de que la única forma de entender un movimiento de la magnitud del iniciado por Túpac Amaru II, es comprendiendo muy bien las fuentes (Szeminski, 1983: 9), es decir, y considerando los propósitos de la primera parte, el significado de los términos que designan la pertenencia de los insurrectos a uno u otro grupo social. Una de las hipótesis explicaría lo anterior: "En la época de la insurrección coexistieron en el Perú cuatro jerarquías sociales distintas, paralelas y no superpuestas; una jerarquía estamental, una de castas, una cultural y otra de clases y estratos sociales" (Szeminski, 1983: 10). En estas últimas figuran los conceptos de: indio, mestizo, cholo, español, zambo, mulato (casta); noble, español, cacique, principal, inca, tributario, mitayo (estamentos); hacendados, campesinos, pobres, ricos, corregidores, mercaderes, obrajeros (clases). Tomando en consideración que en los documentos existiría una diferenciación social bastante particularizada es pertinente preguntarse, en la medida que los rebeldes (nos referimos a los que sabían escribir) son los productores de los edictos que señalan a tales divisiones, ¿qué tipo de tradición incaica era pensada por los rebeldes y cómo estos pensaban las distintas divisiones sociales que incluían a no indígenas? ¿Es posible asumir una visión indígena en la práctica discursiva de los dirigentes de la rebelión, cuando incluyen en sus proyectos a una sociedad fragmentada en sus adscripciones identitarias?

En las conclusiones del primer capítulo aparecen algunas apreciaciones que quisiéramos discutir en torno a la composición social del virreinato peruano en el período de la insurrección, su relación con el programa rebelde y la visión indígena de las divisiones sociales.

Nos parece que es relevante la presencia de divisiones percibidas y representadas en los textos por las autoridades rebeldes (nos referimos obviamente a los documentos trabajados por Szeminski), pues si consideramos que los documentos y lo que allí está descrito representan efectivamente la situación sociocultural existente en el centro sur andino del siglo XVIII, podemos inferir que existían diferencias comprendidas y asumidas por la población indígena y española, lo que complejiza el estudio de la sociedad colonial y su conformación dinámica y entretejida. Esta afirmación, apuntala las perspectivas histórico/antropológicas que consideraron seriamente la oposición generalizante de dos culturas, naciones o "civilizaciones" en un período claramente tardo colonial. Tal supuesto epistemológico guiaría la expurgación documental de Szeminski en la búsqueda de una estructura de pensamiento prehispánica en los bandos y edictos emitidos por los rebeldes, es decir, por el propio Tupác Amarú II y sus más cercanos 
colaboradores. Del análisis de los documentos que reflejan una ordenación de los contenidos con una lógica hispana, Szeminski afirma que los autores de tales fuentes:

Consideraban a la sociedad como compuesta de dos civilizaciones, culturas y naciones: indios y españoles. Algunos, la consideraban como compuesta de tres grupos nacionales: Chapetones, españoles, criollos e indios" [...] Creían que esta misma sociedad estaba compuesta de varias castas: indios abajo, "gente de casta" en el medio, los negros también abajo, los mestizos mucho más arriba y en la misma cima los españoles (Szeminski, 1983: 56).

Desde el punto de vista de la separación en cultura y en casta, la sociedad colonial podría ser distinguida en la tradicional frontera que separa dominadores y dominados. No obstante, si la construcción social se efectúa a partir de la división de los estamentos, se puede describir a

Gente flotante-forasteros, que quedan fuera de la jerarquía; indios tributarios (campesinos de las comunidades), cholos, zambos y mestizos, que constituyen la "burguesía", en la cual los mestizos son los patricios y los cholos y zambos, la plebe, estamento intermedio entre tributarios y nobles, es decir, españoles, entre los cuales se incluía también el Inca, ñusta y quya, así como a los caciques y principales. Un poco aparte, veían a los esclavos llamados también negros y a los eclesiásticos, es decir, a los sacerdotes (Szeminski, 1983: 56).

Un asunto de relevancia es que la élite noble indígena podía estar siendo designada dentro del grupo de los españoles, separada en términos de estamento de los indígenas tributarios. Nos preguntamos si de ser correcta la presencia de tal clasificación y diversidad social en la percepción de los insurrectos, ¿cómo pervivió una visión indígena que representara a los indígenas, paralelamente a una separación estamental operada por los hispanos, en la que los propios indígenas podían diferenciarse? ¿Es posible pensar que el programa se sustenta sólo en la lógica social que el contexto histórico del siglo XVIII le otorgaba y que, por lo tanto, la división de dos sociedades homogéneas internamente (en el siglo XVI) fuese modificada por el "tiempo" colonial?

Al respecto, la "utopía", desde el punto de vista de las divisiones sociales presentes en los documentos, ¿a quién estaría dirigida? S. O’Phelan (1995: 13-37) cuestiona la existencia de un programa rebelde que represente los intereses de todos los involucrados o los llamados a involucrarse. Al hablar de las divisiones 
étnicas y de civilización, Szeminski muestra que en los documentos figuran divisiones que no consideran la oposición españoles/indígenas; la presencia de las nociones de "peruano", "indiano" caracterizan una identidad que se va construyendo progresivamente en el siglo XVIII y que remite peregrinamente a una nacionalidad común vinculada a la territorialidad (Anderson, 1993). Los edictos rebeldes hacen uso de esta categoría en la que se pretende incluir a los criollos y a los mestizos en oposición a los españoles de España. Por otro lado, se hace referencia a grupos identitarios que no necesariamente comparten una base étnica, sino sus apelativos se asocian al nombre de un lugar; arequipeños (de Arequipa), limeños, cochabambinos, cusqueños, pocoatas (de Pocoata), machas (de Macha). Sabido es que tales acepciones que remiten a un espacio geográfico y que homologan una determinada identidad a la tierra nominada, son rasgos clasificatorios propios del discurso español cuando este refería a la naturaleza de las distintas naciones (Martínez, 2011). J. G. Thupa Amaro inicia su famoso "Bando de la libertad de los esclavos" con las palabras:

Hago saber por éste a los peruanos vecinos estantes y havitantes de la ciudad del Cusco paysanaje de españoles y mestizos, religiosos de todas las que contiene dicha ciudad, clérigos y demás personas distinguidas que hayan con traído amistad con la Gente peruana concurren en la distinguida empresa que hago favorable al bien común de este Reyno por constarme las hostilidades y vejámenes que se experimenta de toda gente europea (Szeminski, 1983: 50).

La peruanidad a la que alude el Inca Tupa Amaro se refiere, al parecer, a la tierra y a la nación. Tales conceptos involucran rasgos identitarios que se alejan de un soporte étnico y cultural homogéneo. En el contexto del método, las divisiones sociales existentes en el siglo XVIII a las que hacen referencia los edictos y bandos rebeldes aparecen en documentos pensados en español y se enuncian a partir del contexto social-político de los hispanos. Nos parece que el tratamiento de esta primera parte considera una aproximación histórica que contextualiza el discurso rebelde en el seno mismo del proceso colonial. No obstante, para Szeminski habría también un porcentaje de población que participó en los acontecimientos de habla quechua y aymara, más allá del lenguaje oficial de resistencia. En ambos dialectos existe la posibilidad, para el autor, que exista en pleno siglo XVIII una visión de la historia que tiene antecedentes prehispánicos y que estaría en el programa rebelde configurando la parte central de éste, es decir, cómo los rebeldes miraron la historia, cómo se incluían en ella, y cómo la representaban a partir de una tradición ancestral. Parte de estas aseveraciones se incluyen en la segunda parte, y aquí se presupone un supuesto de continuidad y, para comprobarlo, se acude a tratamientos disciplinarios 
más allá de la historia y más allá del siglo XVIII.

\subsection{Las fuentes, la visión indígena y el problema de la continuidad; de Guaman Poma de Ayala y los cronistas del XVI a la tradición oral del siglo XX}

Si el primer capítulo se define a partir de un tratamiento histórico que intenta entender los conceptos en el contexto en que éstos son producidos y que además se acude a un cuerpo homogéneo de datos de un mismo fondo documental, la segunda parte se aboca a los mismos documentos, pero ya no entendidos en su propia lógica, sino a partir de fuentes heterogéneas en su naturaleza y temporalmente distantes entre sí. Por otra parte, la mirada sobre los textos coloniales implica una tensión epistemológica; la segunda parte supone el hecho colonial y lo supera en la búsqueda de un "sistema" de pensamiento andino que goza de una asombrosa continuidad.

La argumentación central de Szeminski es considerar que, si bien el programa rebelde asumía la religión católica, los adelantos técnicos traídos por los españoles, la estructura de poder monárquico, entre otras, existían al interior del mismo prácticas que indicarían la presencia de una "mentalidad" indígena distinguible del "pensar en español" (Szeminski, 1983: 83). Supone como principal hipótesis "la presencia, entre los insurgentes, de una visión de la historia completamente diferente de aquella hispano-católico-europea" (Szeminski, 1983: 84). Esta visión tendría que ver con la representada en tiempos del tawantinsuyu y que se refiere a la ordenación del tiempo-espacio. Desgraciadamente, como el autor lo señala, las fuentes directamente relacionadas con la insurrección suministran solamente informaciones fragmentarias, que pueden ser interpretadas sólo si se dispone de algún punto de referencia.

Los puntos de referencia a la imposibilidad documental de las fuentes del siglo XVIII corresponden a dos concepciones de la historia que, según Szeminski, representan la visión prehispánica. Por lo tanto, asumimos que para el autor las visiones de la historia de estas dos fuentes referenciales pueden ser utilizadas para entender los documentos emitidos en español por los rebeldes. Una de ellas es la recogida por Felipe Guaman Poma de Ayala a finales del XVI y principios del XVII5, la otra corresponde a la versión del indígena Abdón Yaranga Valderrama, comunero en 1972 de Huancaraylla en la provincia de Vilcas Huaman (actual departemento de Ayacucho). Siguiendo a Szeminski, ambos textos son muy similares entre sí, puesto que "Guaman Poma de Ayala era igualmente originario de Vilcas Huamán, se puede suponer que el texto anotado en 1972 es el desarrollo de un mismo texto ya conocido desde el siglo XVI en la misma provincia” (Szemnski, 1983: 84). La

${ }_{5}^{5}$ La obra de Guaman Poma de Ayala corresponde a la famosa Nueva corónica y buen gobierno, escrita por el autor a partir de 1570 aproximadamente, y terminada alrededor de 1615. 
vinculación estratégica propuesta por el autor permite argumentar que los documentos tupamaristas pueden ser interpretados y entendidos desde dos lógicas discursivas distintas; una, de carácter textual, intervenida por una fuerte raigambre cristiana y, otra, sujeta a la experiencia etnográfica a partir del registro oral. Ante tales afirmaciones cabría preguntarse: ¿Es posible que dos fuentes de distinta naturaleza puedan ser consideradas para interpretar un programa rebelde del cual se asumen ciertos principios andinos? El compartir un mismo origen territorial ¿es condición sine-qua-non de la producción de un mismo contenido?

A falta de otras fuentes Szeminski acude a dos discursos históricos para explicar un tercero, pasando por alto las condiciones de producción en que son elaboradas las dos versiones. En efecto, los estudios sobre la nueva crónica evidenciaron las influencias culturales con la que esta última sería escrita (Adorno, 1989). En tal sentido, Serge Gruzinski radicalizó una posición metodológica en que era prácticamente imposible acceder, a partir de las fuentes escriturales tempranas, a las contenidas de una tradición precolombina. Según él, se pasaron por alto la revolución de los modos de expresión, el paso de los registros prehispánicos (oralidad y pictografía) a la escritura alfabética (Gruzinski, 1995: 10). Si situamos a Guaman Poma en el contexto en que escribe, a quién se está dirigiendo, las pretensiones de su discurso, no podemos pensar que es un fiel espejo de la cultura de la cual desciende: su obra debe ser mirada como el reflejo de una modalidad de colonialidad del saber (Walsh, 2005), desplegada como uno de los mecanismos de dominación colonial. La condición india del cronista no autoriza a Szeminski a proponerlo como un receptor colonial de la tradición incaica. Lo mismo valdría, y con mayor razón, para la cronística andina producida por los españoles durante la conquista, sujeta a formas de representación propias de los estilos narrativos que gobernaban las producciones textuales durante el siglo XVI y que no necesariamente traslucían los principios culturales andinos en un contexto de traducción y resignificación histórica de los mismos.

Siguiendo la misma argumentación, la tradición oral rescatada en 1972 en clave etnográfica fue usada como "dato" comprobatorio de una percepción indígena del tiempo y el espacio invariante al devenir histórico. Las críticas de Mark Thurner (1998: 459-485), en este sentido, parecen pertinentes a una etnohistoria que vinculó sin cambios sustantivos los siglos XVI y XX, olvidando los procesos de conformación de las identidades étnicas en la colonia (Wachtel, 1997: 677-708). La analogía etnográfica practicada por investigadores cercanos a la antropología y que supuso la comparación de material etnográfico con documentos históricos, como la aplicación de información histórica contemporánea para entender material arqueológico, fue riesgosa en cuanto legitimó la certeza de la continuidad en ámbitos específicos de la cultura, imponiéndole al pensamiento andino una estabilidad casi geológica. 


\subsection{De la visión indígena sobre del tiempo-espacio en el XVIII; una aproximación antropológica a un problema histórico}

Si de estar implícita una visión indígena en el programa rebelde ¿Cuál es esta visión? ¿Cómo ha sido reconstruida? ¿A partir de qué fuentes se ha podido constituir un "sistema" de pensamiento sobre el tiempo-espacio en épocas prehispánicas? Y, a partir de esto último, ¿cómo puede un sistema de pensamiento estar reflejado sobre las restituciones que históricamente efectúan los rebeldes? Volviendo a Szeminski:

Dos concepciones de la historia me han servido en la búsqueda que he adelantado y que tiene por objetivo establecer que conceptos referentes al tiempo y a la historia funcionaban en el antiguo Perú y cuál fue la relación de estos conceptos con la visión del presente, es decir, como influía la descripción propia de la situación del individuo y de su grupo en la representación y calificación del presente, pasado y futuro. Entre aquellos conceptos, más precisamente, en las representaciones de la realidad presente y pasada, he buscado el porqué los movimientos campesinos en las tierras del Tawantinsuyu, manifiestan la necesidad de reconstruir el tawantinsuyu (Szeminski, 1983: 85).

Para el autor, la categoría tiempo-espacio correspondería a un sistema de pensamiento que se adquiere en el seno del grupo familiar, es por ello que considera necesario partir analizando las estructuras familiares andinas como sistemas de clasificación. Sin embargo, admite la imposibilidad de que la familia y su organización, como las concibiese la sociedad incaica, se mantuviesen en la colonia. Para esta imposibilidad centra su análisis sobre un objeto particular, en el cual es posible reconocer cierta continuidad:

Las estructuras de parentesco, la organización de la aldea, al igual que la tradición y la actitud frente al pasado, son algo casi tan perdurable como la cultura de la cuál forma parte; Por esto resulta mejor comenzar por la organización familiar y del sistema de parentesco aún no modificado por la injerencia europea (Szeminski, 1983: 89)6.

Los sustentos teóricos y metodológicos para desentrañar la organización social en épocas prehispánicas son tomados del uso antropológico que Tom Zuidema (1995) le diera al material etnográfico, documental y cronístico para reconstruir la

\footnotetext{
${ }_{6}^{6}$ El subrayado es nuestro.
} 
organización social del Cusco incaico. Szeminski reconstruye un sistema, habla de estructuras sociales y las proyecta, en cuanto sistema de pensamiento, al contexto del siglo XVIII. La composición de un sistema social-espacial en la perspectiva de Zuidema responde al intento de desentrañar la lógica del pensamiento nativo anterior a la colonización ibérica, considerando fuentes documentales españolas, mestizas e indias (Zuidema, 1995). En este sentido, la preocupación del distinguido antropólogo holandés, al parecer, no es la historización de una práctica producto de una mentalidad determinada, sino la conformación de una estructura de pensamiento alejada de transformaciones esenciales. En la lógica de razonamiento del programa de Tupac Amaru II, Szeminski supone que las "estructuras" de clasificación social son definidas, en 1780, del mismo modo a la representada por los incas en períodos prehispánicos.

La organización familiar y el sistema de parentesco en el Cusco eran determinados por los siguientes principios: a) división en tres Grupos; Qullana, Payan, Qayaw, b) división en cuatro grupos llamados Suyu, c) división en dos grupos llamados Saya, de los cuales llamaron a uno Hanan y al otro Urín, d) división en cinco o diez grupos llamados de diversas maneras dependiendo a quien se clasifique, e) pertenencia del individuo al grupo llamado Ayllu, endogámico y patrilineal, f) pertenencia del individuo al grupo llamado Panaka, exogámico y matrilineal. Sigamos ahora los documentos: Guaman Poma de Ayala y los cronistas del siglo XVI.

Consideremos la interpretación que los cronistas y Felipe Guaman Poma de Ayala hicieron de la clasificación del tiempo en épocas prehispánicas en función de sus improntas cristianas y sus traducciones a escenarios nativos, intervenidos por el paso de la oralidad a la escritura (Ong, 1997). El principio de la división en cinco es tomado en consideración para la construcción de las “edades andinas", verdaderos símiles de las edades bíblicas (González, 2012: 378). Una serie de cronistas de los siglos XVI-XVII, en particular Fernando de Montecinos, describen cinco humanidades que se suceden unas a otras a través de rupturas cosmogónicas llamadas Pacha-Kuti (vuelta del mundo). En este sentido, Felipe Guaman Poma de Ayala en el siglo XVII reconstruía en su crónica las distintas humanidades con características particulares, a saber; a) wari wiracocha runa (antigua gente wiraquca), b) wari runa (gente antigua), c) purun runa (gente del desierto), d) awqa runa (gente guerrera), e) inka runa (gente del inca). Las cuatro etapas originarias son sintetizadas por la dominación civilizadora de los incas, quienes se conforman en la clase dominante. Siguiendo la lógica de los acontecimientos de la conquista, la dominación española abre una nueva era o tiempo "histórico"; f) tiempos de los cristianos, de la conquista $\mathrm{y}$ de los virreyes conocidos en un lugar como wiraqucha kristianu runa (gente cristiana wiraqucha). No obstante, esta tradición, que pretende describir edades andinas, está sustentada en los procedimientos retóricos y en los saberes fundantes que instala la tradición escolástica. Se han estudiado las influencias narrativas que el 
cronista andino recibió para elaborar su Nueva corónica y buen gobierno en el contexto del Perú virrenal post-toledano (González: 2012).

La pretensión de Szeminski es afirmar que las edades andinas, cuya articulación está definida por el tiempo cíclico en la que cada humanidad sería destruida por un pachakuti o vuelta de mundo, tienen cabida hermenéutica en la explicación que los insurrectos daban del tiempo-espacio en función de la existencia de un nuevo orden de cosas que la rebelión estaba a punto de consolidar. Si la presencia del sistema colonial había cambiado el orden incaico, instaurando un mundo o pacha en que los indios eran los oprimidos, la rebelión antifiscal se presentaba como la restitución violenta a ese orden utópico. En este sentido, la lógica del cambio, en pleno siglo XVIII, obedecía más a un principio milenarista, construido sobre la base de un pensamiento mítico, que a las condiciones históricas que gatillaron un descontento generalizado en el Perú virreinal borbónico. El pasado prehispánico debía ser memorizado en torno a los principios del tiempo cíclico en el que una vuelta de mundo era perfectamente esperable en el futuro.

Ahora bien, nos preguntamos, el sistema de clasificación social y temporal ¿fue asumido y comprendido por los rebeldes que emitían los documentos? Un sistema de pensamiento originario, ¿Pudo operar conscientemente en el programa que habla de restituciones de orden coyuntural? ¿Hasta qué punto el proceso colonial no somete las reglas y principios de clasificación referidas a una concepción del tiempo y la historia en la visión indígena del siglo XVIII?7 Con todo, ¿cómo soluciona Szeminski el clásico problema entre estructura e historia? (Wachtel, 1973, p. 13-54).

\section{Un sistema de pensamiento incaico presente en la rebelión de Tupac Amaru}

Para Jan Szeminski, la presencia de un "sistema" de pensamiento incaico operaría en forma paralela a una imposición cultural española (Szeminski, 1983: 159-160), es decir, ambos sistemas de pensamiento no son excluyentes en los propósitos de restitución de los rebeldes. Ahora bien ¿cómo se manifiesta tal perduración en pleno siglo XVIII? Citemos la solución propuesta por el autor "Si el empleo de los conceptos que le son propios (se refiere al uso de las "voces" indígenas) es muestra que un sistema ideológico perdura, es preciso buscar de una

\footnotetext{
7 Bastante se ha escrito sobre la enseñanza religiosa a los caciques en el siglo XVIII. Nos preguntamos si el programa rebelde no refleja todo el proceso de asimilación de las formas de expresar un saber que estaban en boga durante el siglo XVIII y que se relacionan a la educación española que recibían los curacas, incas, entre otros. Nos inclinamos a pensar que las fuentes del siglo XVIII, en particular los usos indígenas que allí aparecen, no son reflejo directo de una restitución prehispánica, sino expresan su realidad inmediata: realidad que habla de una restitución imaginada del tawantinsuyu, es decir, un incario construido con las lógicas peninsulares.
} 
manera lógica las huellas de la organización familiar incaica en los archivos parroquiales" (Szeminski, 1983: 159).

Partiendo con la continuidad de lo que denomina "organización tipo Cusco", Szeminski encuentra que el uso permanente de voces indígenas permite llegar a la conclusión de que tales usos y denominaciones de los sistemas de parentesco en el siglo XVIII poseían el mismo sentido clasificatorio que en épocas del inca. En documentos referidos a las partidas de nacimiento de la familia Tupac amaru, como en el otorgamiento de poderes que hacen los caciques de Yanaoca a Tupaca Amaru, el autor, a partir de la existencia de conceptos similares a los que reconstruye Zuidema, establece que

de manera evidente aparecen tanto la patrilinealidad como la matrilinealidad, la edogamia Qullana y la división en hanan saya y urin saya. Puesto que hay Ayllus definidos como qullana y otros definidos con nombre propio, se puede afirmar que la clasificación qullana-payan-qayaw existía aún (Szeminski, 1983: 162).

La presencia de una serie de términos en los documentos que remiten a una clasificación parental incaica, es tomada en forma literal y asumida tal como lo hiciera Tom Zuidema en la reconstrucción de un sistema de pensamiento preincaico. Un cuestionamiento necesario es preguntarse si efectivamente los términos, en el contexto colonial, definen con las mismas reglas las jerarquizaciones sociales y las legitimidades al poder. Se acude a un modelo más bien "estático" (no dinámico) para entender las reglas de clasificación que supuestamente están expresando los documentos.

Atendiendo a lo que señalábamos más arriba sobre las divisiones sociales también expresadas en los documentos de la insurrección, es posible que de existir conceptos que estén refiriéndose a "realidades" sociales, ellos deben entenderse también en términos de la compleja red de clasificaciones existentes y asumidas en el siglo XVIII (cholos, mestizos, forasteros, etc.). Es dudoso sostener que el sistema de clasificación incaico, en tanto modelo de representación, pueda haberse mantenido hermético sin tomar las designaciones coloniales, sobre todo cuando éstas eran usadas para legitimaciones del poder, acceso a cargos y reivindicaciones en el marco de las reglas peninsulares.

\section{A modo de epílogo}

La utopía tupamarista fue elaborada en una década en que la antropología cultural pretendía cierta legitimidad en la interpretación de los fenómenos históricos adjudicados al período colonial. Asumiendo la continuidad cultural y el esencialismo 
como paradigma analítico, los historiadores enarbolaron las banderas del indianismo como una expresión cultural distante a la compleja red de relaciones sociales (étnicas, estamentales) que consolido el período tardo colonial en la América hispana. Más allá de pensar, como lo hicieron Burga, flores Galindo y Rowe, que la restitución del incario operaba estratégicamente en el plano de una comunidad imaginada (Anderson, 1993), Szeminski instaló con fuerza la posibilidad de que las estructuras de pensamiento, las estructuras de parentesco y la percepción del tiempo espacio se mantuviesen inalteradas en un porcentaje no despreciable de indígenas participantes de la gran rebelión. La intención interpretativa de este tipo de continuidad lo llevó a comparar un corpus documental, propio del siglo XVIII, con los discursos de la colonización temprana y con la tradición oral emitida por las comunidades campesinas contemporáneas. Se asumió, entonces, que las referencias legítimas a los bandos y edictos rebeldes podían estar contenidas en otro tipo de relatos, cuya naturaleza exigía otro tipo de táctica heurística, ya que el contexto de su propia producción obedecía a otras coyunturas de enunciación.

Más allá de una mirada esencialmente materialista del proceso insurreccional, existe la posibilidad de que la sociedad andina no sólo pudo lograr rearticular su ética económica a las imposiciones coloniales -rompiendo con la supuesta continuidad de la organización económica del estado inca-, sino que en la relación económica del estado colonial con la sociedad peruana virreinal es posible reconocer una dimensión social que elude la oposición indígenas/blancos (entendidos como españoles), sobre la que insiste Jan Szeminski. Las demandas y disconformidades sociales producto de las reformas económicas impuestas por la Corona, surgen paralelamente entre castas distintas de las que participan criollos, mestizos e indígenas. Los documentos referentes a los bandos y edictos rebeldes como a los juicios y disposiciones reales (referidos a la región nuclear de la insurrección), permiten inferir una participación insubordinada de criollos y mestizos al lado del inca Tupac Amaru II. Esto, más allá de las rígidas fronteras étnicas sobre las que se quiere oponer a españoles e indígenas. Las reivindicaciones del Inca con su pueblo incorporan varios elementos de orden hispano, consolidados a finales del XVIII (uno de ellos puede ser el tributo), como la inclusión de otras castas en el nuevo orden socioeconómico que los rebeldes indígenas pretendían llevar a cabo. Con todo, el proceso tupamarista y las lógicas discursivas que le dieron un estatuto políticoreivindicativo, deberían ser ponderadas en el contexto de las reformas borbónicas y las nuevas condiciones tardo-coloniales que afectaron a un grupo social importante y diferenciado, en el centro sur peruano de fines siglo XVIII. En este sentido, las hipótesis que han afirmado la existencia de continuidades del pensamiento andinoprehispánico instaladas en los bandos y documentos rebeldes, deben ser cuestionadas. Con ello se hace justicia, por lo tanto, a los contextos históricos de producción y al hecho de que el proceso colonial -en tanto estructura- logró 
performar y adaptar las identidades étnicas a identidades colectivas basadas en otros criterios (no necesariamente étnicos) de adscripción sociocultural -como la residencia y la localidad- legitimadas por la administración hispana en América.

\section{Bibliografía}

Adorno, R. (1989): Cronista y Príncipe. La obra de Don Felipe Guaman Poma de Ayala. Lima, PUCP, $276 \mathrm{p}$.

Anderson, B. (1993): Comunidades imaginadas. Reflexiones sobre el origen y la difusión del nacionalismo. México, FCE, 315 p.

Bouysse-Cassagne, T. y Harris, O. (1987): "Pacha: en torno al pensamiento Aymara", en 0. Harris (org.), Tres reflexiones sobre el pensamiento andino. La Paz, Hisbol, pp. 15-40.

Burke, P. (1996): Formas de hacer Historia. Madrid, Alianza editorial, 310 p.

Burga, M. (1988): Nacimiento de una utopía; muerte y resurrección de los incas. Lima: Instituto de Apoyo Agrario, $449 \mathrm{p}$.

Cornejo, J. (1949): Túpac Amaru. La revolución precursora de la emancipación continental. Cuzco, Universidad Nacional de Cuzco, 190 p.

Fischer, J. (1974): La rebelión de Túpac Amaru y el programa de la reforma imperial de Carlos III. Anuario de Estudios Americanos, 28, pp. 405-421.

Flores Galindo, A. (1987): Buscando un Inca: identidad y utopía en los Andes. Lima, Instituto de Apoyo Agrario, $433 \mathrm{p}$.

Golte, J. (1980): Repartos y rebeliones: Túpac Amaru y las contradicciones de la economía colonial. Lima, IEP, 256 p.

González, S. (2012): Guaman Poma y el repertorio anónimo (1554): una nueva fuente para las edades del mundo en la nueva corónica y buen gobierno. Revista Chungará, 44(3), pp. 377-388.

Hidalgo, J. (1982): Fases de la rebelión indígena de 1781 en el corregimiento de Atacama y esquema de la inestabilidad política que la precede 1749-1781. Revista Chungará, 9, pp. 192-246. 
Lewin, B. (1957): La Rebelión de Túpac Amaru y los orígenes de la emancipación americana. Buenos Aires, Hachette, 1023 p.

Martínez, J.L. (2011): Gente de la tierra de guerra. Los lipes en las tradiciones andinas y el imaginario colonial. Lima, PUCP/DIBAM, $419 \mathrm{p}$.

Ong, W. (1997): Oralidad y escritura. Tecnologías de la palabra. México, FCE, 191 p.

O’Phelan, S. (1988): Un siglo de rebeliones anticoloniales. Perú y Bolivia, 1700-1783. Cusco, Centro de Estudios Regionales Andinos Bartolomé de las Casas, 351 p.

O'Phelan, S. (1995): La gran rebelión de los Andes. De Túpac Amaru a Túpac Catari. Cusco, Centro de Estudios Regionales Andinos Bartolomé de las Casas, 237 p.

O'Phelan, S. (1997): Kuracas sin sucesiones. Del cacique al alcalde de indios: Perú y Bolivia,1750-1835. Cusco, Centro de Estudios Regionales Andinos Bartolomé de Las Casas, $100 \mathrm{p}$.

Serulnikov, S. (2010): Revolución en los Andes. La era de Túpac Amaru. Buenos Aires, Sudamericana, $218 \mathrm{p}$.

Szeminski, J. (1983): La utopía tupamarista. Lima, PUCP, 297 p.

Thurner, M. (1998): "Después de la Etnohistoria. Desencuentros y reencuentros entre discursos antropológicos e históricos", en Actas del IV Congreso Internacional de Etnohistoria. Tomo II. Lima, Ed. PUCP. pp. 459-485.

Valcárcel, C. (1977): Túpac Amaru, precursor de la independencia. Lima, Universidad Nacional Mayor de San Marcos, 201 p.

Wachtel, N. (1997): "Nota sobre el problema de las identidades colectivas en los Andes meridionales", en R. Varón y J. Flores (org.), Arqueología, antropología e historia en los Andes; Homenaje a María Rostworowski. Lima, IEP, p. 677-708.

Wachtel, N. (1973): Sociedad e Ideología. Ensayos de cultura andina. Lima, IEP, 228 p.

Walker, C. (1999): De Túpac Amaru a Gamarra: Cuzco y la formación del Perú Republicano 1780-1840. Cusco, Centro de Estudios Regionales Andinos Bartolomé de Las Casas, $314 \mathrm{p}$.

Walsh, C. (2007): ¿Son posibles unas ciencias sociales/ culturales otras? Reflexiones en torno a las epistemologías decoloniales, Nómadas, 26, pp. 103-112. 
Zuidema, T. (1995): El sistema de Ceques del Cusco. La organización social de la capital de los Incas. Lima, PUCP, 420 p.

Fecha de recepción: 20 de noviembre de 2019

Fecha de aceptación: 27 de diciembre de 2019 